\title{
The use of tire rubber in the production of high-performance concrete
}

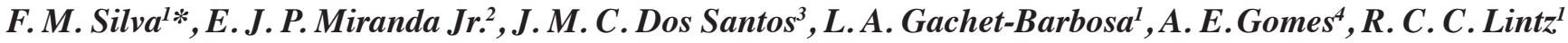 \\ ${ }^{1}$ University of Campinas, FT, R. Paschoal Marmo 1888, 13484-332, Limeira, SP, Brazil \\ ${ }^{2}$ Federal Institute of Maranhão, EIB-DE, 65010-030, São Luís, MA, Brazil \\ ${ }^{3}$ University of Campinas, FEM-DMC, 13083-970, Campinas, SP, Brazil \\ ${ }^{4}$ Federal University of Itajubá, 37500 903, Itajubá, MG, Brazil
}

\begin{abstract}
The advances in concrete technology lead to the search for alternative materials that provide improvements in concrete properties while at the same time collaborating with sustainable practices in construction. In this study, the influence of the incorporation of waste tire rubber on the mechanical properties of high-performance concrete was discussed. The waste rubber from the tire retreading process was used in partial substitution of the fine aggregate (sand) in the percentages of $7.5 \%, 15 \%$ and $30 \%$ with respect to the mass of the sand. For the characterization of the concrete, the following tests were carried out: water absorption, void index, specific density, compressive strength, flexural tensile strength, modulus of elasticity and microscopy analysis. The incorporation of rubber as aggregate in high-performance concrete proved to be promising for the production of a structural concrete with special characteristics, besides collaborating with the proper disposal of waste tires.
\end{abstract}

Keywords: alternative materials, high-performance concrete, sustainability.

\section{INTRODUCTION}

The high-performance concrete (HPC) is an improvement of conventional concretes. Its composition consists of good quality common aggregates, common Portland cement, the initial high strength cement can be used, and the silica fume between $5 \%$ to $15 \%$ in relation to the mass of the cement. Other cementitious materials may be used, such as fly ash or granulated blast furnace slag and a superplasticizer additive should always be used [1]. The difference between HPCs and conventional concretes is the very low water/cement ratio. Values below 0.35 are generally used. The HPCs are very dense and have a low volume of capillary pores, that is, they have a compact microstructure, including the transition zone between the cement paste and the coarse aggregate, resulting in a thin or absent transition zone, which provides greater strength and durability $[1,2]$. The concept 'high performance' is not only limited in terms of strength, but it is also related to safety, quality of life, sustainability, which encompasses the reduction of natural resources, energy, labor, materials, and costs [3].

In recent years, the construction industry is taking on the challenge of incorporating sustainability into production activities by seeking environmentally friendly raw materials or by using solid waste as concrete aggregates. The waste tire is an environmental liability and its appropriate destination is a worrying obligation for Brazil and the world, as it is a material of difficult degradation and storage. Currently, the activity that consumes the most part of waste tires is the use of the tire as fuel in the blast furnace coprocessing in cement industry, papermakers or energy companies. However, this

*faby_febs@yahoo.com.br

(D) https://orcid.org/0000-0001-5968-0360 type of activity must be carefully controlled as it generates hazardous pollutants such as dioxins and furans [4-8]. One of the possible solutions for the appropriate destination of waste tires is the use of the tire rubber crushed in Portland cement concrete to replace some natural aggregates. This attempt could be more environmentally friendly as it helps to eliminate waste tires and avoids environmental pollution [9]. The great disadvantage of using rubber as aggregate in the concrete has still been the significant reduction of the strength. On the other hand, the tire rubber provides to the concrete better ductility, better energy absorption and cracking control, reduction of specific mass, and better thermal and acoustic insulation; such properties are also important for high-performance concrete [10-15]. Holmes et al. [14] observed that the compressive strength of concrete without rubber was greater than $50 \mathrm{MPa}$ and with $15 \%$ replacement of the sand by rubber the resistance reduced to $35 \mathrm{MPa}$. Liu et al. [10] verified that the reduction of the compressive strength in the concrete with $15 \%$ substitution of the fine aggregate by rubber was approximately $38 \%$ and in the flexural strength was approximately $18 \%$. Thomas et al. [16] observed that in rubberized concrete with a low water-cement factor, such as 0.30 , the reduction in compressive strength is not as severe as for higher water; concrete with a $20 \%$ substitution of rubber showed a $5 \%$ decrease in compressive strength.

The use of tire rubber particles as aggregate in the concrete showed promising results in producing a new type of concrete that has relatively improved the criteria of energy absorption and fracture compared to conventional concrete. These characteristics are very important for highperformance concrete, since due to its high strength, the HPC becomes brittle and the rubber insert improves this property, that is, rubber concrete can absorb more energy 
or suffer greater deformations before rupture [17]. In this context, the objective of this study was to verify the adequate amount of rubber addition that could be inserted in high-performance concrete using the beneficial properties that the rubber could provide to the concrete, however, maintaining the mechanical strength characteristic required for HPC, i.e., compressive strength above $50 \mathrm{MPa}$. The rubber residue from the tire retreading process was used in partial substitution of the fine aggregate (sand) in the percentages of $7.5 \%, 15 \%$ and $30 \%$ with respect to the mass of the sand. For the characterization of the concrete, the following tests were carried out: water absorption, voids index, specific mass, compressive strength, flexural tensile strength, modulus of elasticity and microscopy analysis. It was verified that the incorporation of tire rubber as aggregate in the concrete can be viable for the production of structural concrete with special characteristics, besides collaborating with the appropriate destination of the waste tires.

\section{MATERIALS AND METHODS}

Materials: the materials used for the concrete production were: initial high strength cement from the manufacturer Holcim Brazil; silica fume from the manufacturer Tecnosil, natural sand of quartz origin; rubber from tire retreading from the manufacturer Limercap; two granulometries of gravel (gravel 0) and (gravel 1) of basaltic origin; water from the water supply system of the city of Limeira/ SP and superplasticizer additive Glenium 51 from the manufacturer BASF. The specific and unit masses of the fine aggregates were determined according to NBR NM 52:2009 standard. For coarse aggregate, the specific and unit masses were determined according to NBR NM 53:2009 standard. Furthermore, the specific mass of the cement was determined according to NBR NM 23:2001 standard. The test for granulometric determination of aggregates was performed according to NBR 248:2003 standard and the aggregates were classified according to the NBR 7211:2009 standard. The results of the characterization of the materials are shown in Table I.

Table I - Results of characterization of raw materials.

\begin{tabular}{ccccc}
\hline Material & $\begin{array}{c}\text { Specific } \\
\text { density } \\
\left(\mathrm{g} / \mathrm{cm}^{3}\right)\end{array}$ & $\begin{array}{c}\text { Bulk } \\
\text { density } \\
\left(\mathrm{g} / \mathrm{cm}^{3}\right)\end{array}$ & $\begin{array}{c}\text { Maximum } \\
\text { characteristic } \\
\text { size } \\
(\mathrm{mm})\end{array}$ & $\begin{array}{c}\text { Fineness } \\
\text { modulus }\end{array}$ \\
\hline Cement & 3.07 & - & - & - \\
Silica fume & 2.20 & - & - & - \\
Sand & 2.64 & 1.56 & 1.2 & 1.64 \\
Gravel 0 & 3.00 & 1.56 & 9.5 & 5.78 \\
Gravel 1 & 2.97 & 1.47 & 19.0 & 6.20 \\
Rubber & 1.17 & 0.33 & 4.8 & 3.49 \\
\hline
\end{tabular}

Methods. Concrete mixtures: four different concrete mixtures were produced, i.e., the reference one (Ref) without the addition of rubber, the other three with the replacement of $7.5 \%$ (BR1), $15 \%$ (BR2), and 30\% (BR3) of the sand by rubber. The concrete compositions showed a cement consumption of $434 \mathrm{~kg} / \mathrm{m}^{3}, 10 \%$ active silica in relation to the amount of cement, water-to-cement ratio of 0.35 , and superplasticizer additive content of $1.5 \%$ in relation to the quantity of cement. The dosages of materials are shown in Table II.

Table II - Mixture proportions of fresh concrete (ratio by mass).

\begin{tabular}{cccc}
\hline Concrete mix & Cement & Sand & Rubber* \\
\hline Ref & 1 & 2.18 & - \\
BR1 & 1 & 2.02 & $7.5 \%$ \\
BR2 & 1 & 1.85 & $15 \%$ \\
BR3 & 1 & 1.53 & $30 \%$
\end{tabular}

Complements: for all compositions, the ratios by mass (in relation to cement) were 0.70 for gravel 0, 1.61 for gravel 1, and 0.35 for water, and the contents of additive and silica were $1.5 \%$ and $10 \%$, respectively, both in relation to the amount of cement; * - percentage of sand replaced by rubber.

Molding and curing of specimens: for the concrete mixing process, an inclined-axis mixer with a capacity of $120 \mathrm{~L}$ manufactured by CSM was used. Firstly, the coarse aggregate was introduced, then the water, after Portland cement, superplasticizer additive, fine aggregate, rubber and finally silica fume. Immediately after mixing, the concrete was removed from the concrete mixer and the slump test was performed, before the molding of the specimens. For each concrete mixture 15 cylindrical specimens of $10 \mathrm{~cm}$ in diameter by $20 \mathrm{~cm}$ in height (for compressive strength, modulus of elasticity and water absorption tests) and 2 prismatic specimens measuring $55 \mathrm{~cm}$ long by $15 \mathrm{~cm}$ wide by $15 \mathrm{~cm}$ high (for flexural tensile strength test) were molded. After $24 \mathrm{~h}$, they were demolded, and then subjected to the wet curing process. For the molding and curing of the specimens, the recommendations of NBR 5738:2015 standard were followed.

Concrete characterization: for the characterization of the concretes the following tests were performed: i) slump test according to NBR 67:1998 standard for verification of workability and consistency of fresh concrete; ii) compressive strength according to NBR 5739:2007 standard, with the test performed at 7 and 28 days of curing; iii) tensile strength in flexion at 28 days, according to NBR 12142:2010 standard; iv) static modulus of elasticity at 28 days, according to ABNT NBR 8522:2008 standard; v) water absorption, void index and specific mass of the hardened concrete, according to NBR 9778:2005 standard; and vi) scanning electron microscopy (SEM, VEGA3, Tescan).

\section{RESULTS AND DISCUSSION}

Slump test: for all concrete mixtures, the cone truss rebate test was carried out and the results are shown in Table 
III. The amount of water and superplasticizer additive was kept constant for all concrete mixtures, therefore the value of the abatement varied. It was observed that the rubber caused a decrease in the value of the abatement, which may have occurred due to the lower density of the rubber and consequently lower density of the concrete, and taking into account the gravity factor, the lower specific mass may have influenced the value of the rebate [18]. It is also worth noting that these test results in one-off measures and factors such as temperature and humidity variation are also influential, so that the decrease did not occur in a linear way, since the $30 \%$ substitution of sand by rubber reduced less than the concrete mixture with $15 \%$ of substitution.

Table III - Results of slump test.

\begin{tabular}{ccccc}
\hline Concrete mix & Ref & BR1 & BR2 & BR3 \\
\hline Slump $(\mathrm{mm})$ & 210 & 120 & 70 & 90 \\
\hline
\end{tabular}

Compressive strength: the results are shown in Fig. 1. It was observed that the compressive strength decreased with the increasing percentage of rubber replacement for sand. For 30\% substitution, the decrease in compressive strength at 28 days was $54.8 \%$. However, with up to $15 \%$ replacement the concrete presented resistance above $50 \mathrm{MPa}$, within the acceptable classification for high-performance concrete [2]. At rates of $10 \%$ to $15 \%$ the reduction of mechanical resistance is not severe according to [19]. Silva et al. [20] found that with a $10 \%$ substitution of sand by tire rubber the compressive strength remained similar to concrete without rubber. The hydrophobic nature of the rubber creates a weak interfacial bond between the cement paste and the rubber, causing a decrease in mechanical resistance. The low modulus of elasticity of the rubber, in relation to the other materials constituting the mixture, causes rubber particles to result in weak spots inside the concrete, where there is a higher concentration of stresses and consequently a reduction in strength $[11,21]$.

Flexural tensile strength: the results are shown in Fig. 2a. The flexural tensile strength, as well as the compressive strength, decreased with the increase of the substitution

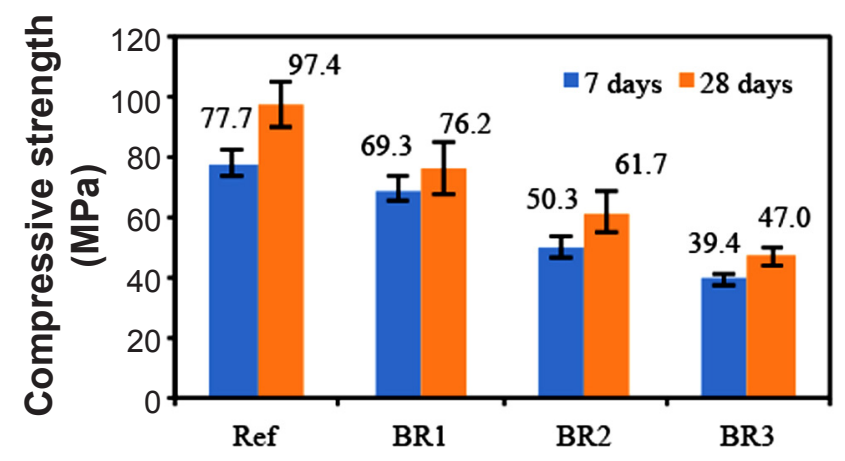

Figure 1: Compressive strength at 7 and 28 days of concrete mixtures. of the sand by rubber, and with a $30 \%$ substitution, there was a decrease of $48.8 \%$. However, with $7.5 \%$ of substitution, there was no decrease in tensile strength in flexion and with $15 \%$ replacement, the fall was $17.7 \%$. The decrease in tensile strength caused by the insertion of the rubber into the concrete was smaller than the decrease in compressive strength. Although there was a decrease in the compressive and flexural strength, the rubber possibly provided improvements in the performance of the concrete for resistance to cracking and fatigue [10]. Static Young's modulus: the results are shown in Fig. 2b. With the addition of rubber content, there was a reduction in Young's modulus of the concrete. However, the concrete with rubber insertion can undergo greater deformation before rupture, that is, an increase in ductility occurs [13, 22, 23].
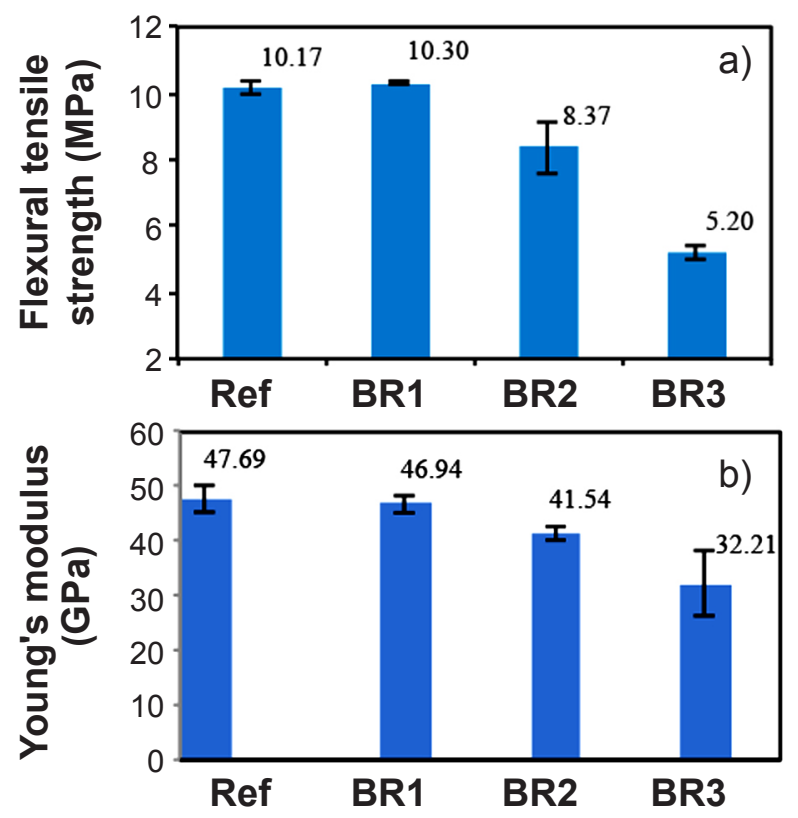

Figure 2: Flexural tensile strength (a) and Young's modulus (b) at 28 days of concrete mixtures.

Water absorption, void index, and specific mass: the results are shown in Table IV. With the increase of the substitution of the sand by rubber, there was an increase in the voids index and the water absorption, which was a consequence of the hydrophobic nature of the rubber that caused greater porosity in the concrete. Due to the lower density of the rubber compared to sand, the increase in rubber tended to decrease the density of the concrete.

Scanning electron microscopy analysis (SEM): Fig. 3 shows the microscopy images of the concrete. It was observed that the insertion of the rubber caused a weakening of the matrix mainly in the transition zone (rubber-paste aggregate), where it was seen the propagation of cracks and higher porosity. Other researchers [24] also verified by microstructure analysis that the transition zone between the rubber aggregate and the cement paste increases around $50 \%$ : with a $10 \%$ substitution of the fine aggregate by 
Table IV - Water absorption, void index and specific mass at 28 days of concrete mixtures.

\begin{tabular}{cccc}
\hline $\begin{array}{c}\text { Concrete } \\
\text { mixture }\end{array}$ & $\begin{array}{c}\text { Water } \\
\text { absorption }(\%)\end{array}$ & $\begin{array}{c}\text { Index of } \\
\text { voids }(\%)\end{array}$ & $\begin{array}{c}\text { Specific mass } \\
\left(\mathrm{g} / \mathrm{cm}^{3}\right)\end{array}$ \\
\hline Ref & 1.53 & 3.79 & 2.57 \\
BR1 & 1.60 & 3.88 & 2.53 \\
BR2 & 1.63 & 3.90 & 2.49 \\
BR3 & 2.79 & 6.37 & 2.44 \\
\hline
\end{tabular}
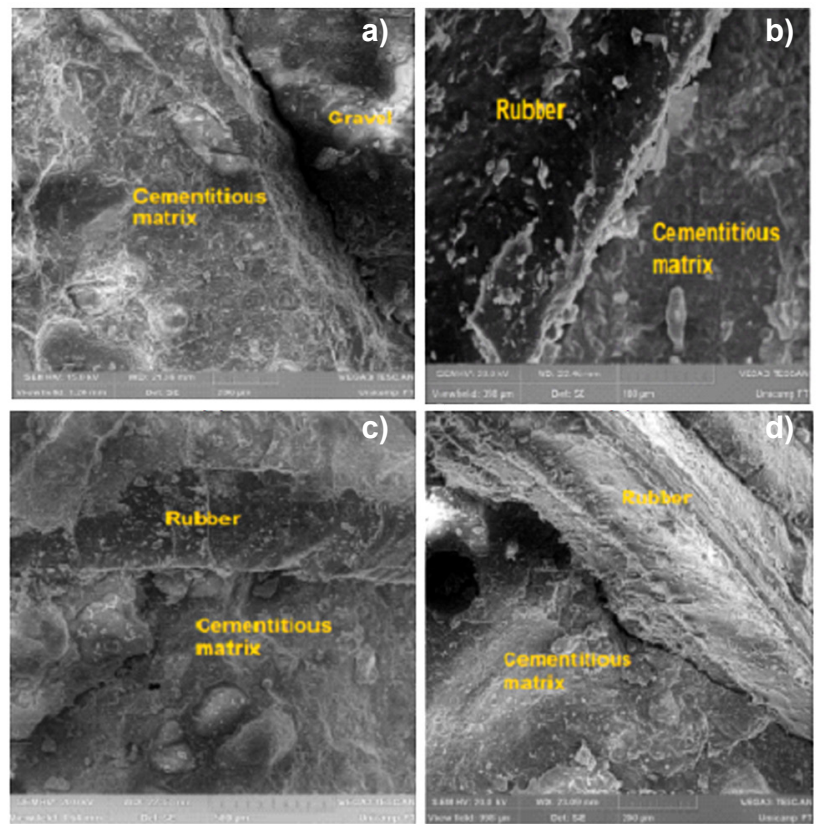

Figure 3: SEM micrographs of: a) reference concrete - without rubber; b) concrete BR1 - 7.5\% replacement; c) concrete BR2 $15 \%$ replacement; and d) concrete BR3 - 30\% replacement.

rubber, the transition zone measurement was $6.65 \mu \mathrm{m}$ while with $50 \%$ replacement it increased to $13.44 \mu \mathrm{m}$. This lack of adhesion between the cement paste and the rubber particles contributes to the weakening of the matrix and consequently to the decrease in mechanical strength.

\section{CONCLUSIONS}

We cannot rule out the possibility of using tire rubber for the production of high-performance concrete (HPC), even with the fact of the decrease of the mechanical resistance. Analyzing the characteristics of the HPC with tire rubber insertion it can be highlighted that: i) the rubber caused a decrease in the workability and consistency of the concrete, a fact observed by the decrease of abatement, especially in the case of high performance concrete, where low water content is used, that is, a change in the characteristics of the constituent materials is a significant influencing factor in the rheological characteristics of the concrete; ii) with the increase of the substitution of the sand by rubber, there was a decrease in mechanical resistance: for the compressive strength at 28 days, the decrease in relation to the concrete without rubber was $21.8 \%, 36.7 \%$, and $51.7 \%$, respectively, for $7.5 \%, 15 \%$, and $30 \%$ replacement; for tensile strength in flexion, there was not decrease with $7.5 \%$ of substitution and for $15 \%$ and $30 \%$ the decrease was, respectively, $17.7 \%$ and $48.9 \%$; for the modulus of elasticity the decrease was $1.5 \%, 12.9 \%$, and $32.5 \%$; iii) it was verified that with the increase of the amount of rubber in the concrete there was an increase in the water absorption and voids index and a decrease in the density of the concrete; iv) the microscopy analysis emphasized the weakening of the concrete matrix with rubber insertion, mainly in the transition zone between rubber-paste aggregate; and v) with up to $15 \%$ replacement of the sand by rubber the concrete mixture proved to be within the standard's classification of mechanical resistance of the high-performance concrete, being a viable alternative for the production of a more sustainable material and for the appropriate destination of the scrap tires.

\section{ACKNOWLEDGMENTS}

The authors gratefully acknowledge: Faculty of Technology-FT for the support and support of the research, to LIMERCAP for the donation of the tire rubber, to TECNOSIL for the donation of the silica fume.

\section{REFERENCES}

[1] A.M. Neville, Concrete properties, $5^{\text {th }}$ ed., Bookman, Porto Alegre (2016).

[2] P.-C. Aitcin, High performance concrete, Pini, S. Paulo (2000).

[3] V. Konkov, Procedia Eng. 57 (2013) 589.

[4] Braz. Inst. Environ. Renew. Nat. Res., Resol. CONAMA $\mathrm{n}^{\circ}$ 416/09, Brasília (2015).

[5] Japan Autom. Tyre Manuf. Ass., "Tyre industry of Japan" (2015).

[6] Eur. Tyre Rubber Manuf. Ass., "End-of-life tyre report" (2015).

[7] Rubber Manuf. Ass., "U.S. scrap tire management summary" (2016).

[8] Z.M.F. Veloso, "Tire life cycle", Min. Envir., Brasília (2013).

[9] B.S. Thomas, R.C. Gupta, Renew. Sust. Energ. Rev. 54 (2016) 1323

[10] F. Liu, W. Zheng, L. Li, W. Feng, G. Ning, Constr. Build. Mater. 47 (2013) 711.

[11] L. Li, S. Ruan, L. Zeng, Constr. Build. Mater. 70 (2014) 291.

[12] J. Lv, Q. Du, H. Wu, Constr. Build. Mater. 91 (2015) 145.

[13] M.R. Hall, K.B. Najim, C.J. Hopfe, Appl. Therm. Eng. 33-34, 1 (2012) 77.

[14] N. Holmes, A. Browne, C. Montague, Constr. Build. Mater. 73 (2014) 195.

[15] A.A. Aliabdo, A.E.M. Abd Elmoaty, M.M. Abdelbaset, Constr. Build. Mater. 91 (2015) 195.

[16] B.S. Thomas, R.C. Gupta, P. Mehra, S. Kumar, Constr. 
Build. Mater. 83 (2015) 320.

[17] F. Liu, G. Chen, L. Li, Y. Guo, Constr. Build. Mater. 36 (2012) 604.

[18] S. Giacobbe, "Study of the physical-mechanical behavior of Portland cement concrete with the addition of tire rubber", M.Sc. Diss., Un. São Paulo, S. Paulo (2008).

[19] A. Moustafa, M.A. Elgawady, Constr. Build. Mater. 93 (2015) 249.

[20] F.M. Silva, L.A. Gachet Barbosa, R.C.C. Lintz,
A.E.P.G.A. Jacintho, Constr. Build. Mater. 91 (2015) 71. [21] X. Shu, B. Huang, Constr. Build. Mater. 67 (2014) 217. [22] L. Lijuan, S. Ruan, Z. Lan, Constr. Build. Mater. 70 (2014) 291.

[23] A. Meddah, M. Beddar, A. Bali, J. Clean. Prod. 72 (2014) 187.

[24] M. Turki, E. Bretagne, M.J. Rouis, M. Quéneudec, Constr. Build. Mater. 23 (2009) 2715.

(Rec. 08/09/2018, Rev. 28/11/2018, Ac. 10/12/2018) 